\title{
Héctor Belascoarán Shayne: el espacio de la ciudad y las masculinidades hegemónicas
}

\author{
4 Cristina Patricia Sosa \\ UNSL/IFDCVM, Argentina \\ cristinap_sosa@hotmail.com \\ Verónica Moreyra \\ UNSL/IFDCVM, Argentina \\ veromoreyra@gmail.com
}

Recibido: 31/72020. Aceptado: 30/12/2020.

\begin{abstract}
Resumen
En este trabajo nos proponemos abordar una serie de novelas de Paco Ignacio Taibo II protagonizadas por Héctor Belascoarán Shayne, personaje en el que hay resonancias de la novela policial negra estadounidense. Intentaremos trazar un perfil del célebre detective desde una perspectiva de género, subrayando en particular el concepto de masculinidad. Nos interesa indagar cómo esta figura y otros personajes que pueblan el universo ficcional construido por el autor encarnan un distanciamiento o se acercan al género en dos de sus sentidos: como matriz de identidad y como forma literaria. Nuestro corpus está compuesto por las novelas Días de combate (1976), No habrá final feliz (1989) y Muertos incómodos (2005), esta última escrita con el Subcomandante Marcos del Ejército Zapatista de Liberación Nacional (EZLN). En constante movimiento por la ciudad de México, espacio en el que reina la impunidad y donde la justicia se vuelve imposible, el detective muestra la sordidez de crímenes que por momentos parecen estar resueltos de antemano; subyace la idea de que todo crimen es crimen de Estado. Mientras vive sus aventuras, Belascoarán Shayne presenta a los lectores un bosquejo de teorización sobre la masculinidad, el ser mexicano y el género policial.
\end{abstract}

Palabras clave: Novela policial; género; detective; masculinidad; México. 


\title{
Héctor Belascoarán Shayne: the space of the city and hegemonic masculinities
}

\begin{abstract}
In this work we intend to approach a series of novels by Paco Ignacio Taibo II starring Héctor Belascoarán Shayne, a character in which there are resonances from the hardboiled fiction. We will try to draw a profile of the famous detective from a genre perspective, highlighting in particular the concept of masculinity. We are interested in investigating how this figure and other characters that populate the fictional universe built by the author embody a distancing or a follow-up / development of the "género" in its two of senses: as an identity matrix (genre) and as a literary form (gender). Our corpus is made up of the novels Dias de combate (1976), No habrá final feliz (1989) and Muertos incómodos (2005), the last one written with Subcomandante Marcos of the Zapatista Army of National Liberation (EZLN). In constant movement through Mexico City, a space where impunity reigns and where justice becomes impossible, the detective shows the sordidness of crimes that at times seem to be solved beforehand, underlying the idea that all crime is a state crime. While living his adventures, Belascoarán Shayne presents to the readers an outline of theorizing about masculinity, being Mexican and the detective fiction genre.
\end{abstract}

Keywords: Hardboiled novel; genre; detective; masculinity; Mexico

\section{Un detective en México}

En su trabajo sobre las obras de Proust, Gide y Genet, el filósofo francés Didier Eribon (2017: 13-14) sostiene que los grandes escritores suelen ser grandes teóricos y que sobre las cuestiones de género o de sexualidad la literatura: "muestra tentativas de teorización [...] mucho más interesantes que las respuestas inmutables que repiten los adeptos a la ideología psicoanalítica". En estas novelas de Paco Ignacio Taibo II, se traza una teoría sobre la identidad mexicana vinculada con una serie de ideas acerca del género policial, así como también sobre la masculinidad.

En una de las primeras escenas de Dias de combate (1976), Héctor Belascoarán Shayne se reúne a comer con una pareja de amigos, Teodoro y Ana María. Hace poco que el personaje abandonó su cómoda posición como supervisor en General Electric y se acaba de separar de su esposa, Claudia. En broma le explica a Teodoro que apellidarse Belascoarán Shayne es motivo suficiente para ser detective, así como ser hijo de un capitán de marina vasco y de una cantante irlandesa de folk. Ana María le responde que, aunque los motivos nombrados deberían ser suficientes, el concepto de detective: "suena muy neoyorquino, muy cosmopolita, poco mexicano" (Taibo II, 1976: 3).

Más adelante, Belascoarán relata cómo fue el proceso de volverse detective independiente, cu enta que tuvo que alquilar un despacho, que intentó conseguir una licencia de detective en un organismo estatal, pero que, frente a la burocracia que eso implicaba, se resignó a comprarla en una academia que daba cursos por correspondencia. Luego agrega que lo que hace cuando investiga es: "Recortar pedazos de todos los periódicos, adivinar, leer entre líneas, reconstruir, reorganizar en la cabeza calles y casas, refabricar ambientes [...] Ir poco a poco creando la idea del cazador, la idea de

\footnotetext{
1 La producción de Paco Ignacio Taibo II ha sido ampliamente trabajada por la crítica literaria. Mientras que algunos han analizado al neopoliciaco como un fenómeno con una identidad propia (Balibrea-Enríquez, 1996), otros han tenido en cuenta los vínculos entre su poética y la de otros autores latinoamericanos (Martín Escribá, Àlex, \& Sánchez Zapatero, J., 2008) y han examinado los lazos entre el discurso de la Historia y la Literatura presentes en su obra (Nichols, 2001).
} 
la presa" (Ibíd.: 3-4). La dinámica de los casos que investiga se caracteriza por ese constante juego de persecución en el que los roles de cazador y de presa se alternan.

Ser un detective en la ciudad de México implica enfrentarse con una serie de obstáculos de los que no dan cuenta ni la literatura ni el cine ni las series de televisión. Significa incluso tener que soportar la desconfianza de los personajes con los que es necesario establecer alianzas. ${ }^{3} \mathrm{El}$ ambiente de inseguridad en el que se mueven lleva inevitablemente a la suspicacia. Por ese motivo, tiene que aclarar en numerosas ocasiones que es independiente, para anular de esa manera cualquier asociación con la policía o con organismos del Estado.

En este sentido, su hermano menor, Carlos Brian, le advierte en relación con su primer caso que es evidente que se quiere matar porque lo que está haciendo en realidad no es perseguir a un asesino de mujeres, sino enfrentarse a un poder mayor. Carlos considera que está jugando en el borde del sistema, desconfía de las motivaciones de su hermano y cree que ha inventado un asesino idealizado que también pretende estar fuera de las reglas del juego. Concluye con una advertencia:

Ten cuidado, no te vayas a encontrar a alguno de los artífices del juego. Cuídate del comandante de la judicial, que en sus horas libres, las horas que le sobran de golpear estudiantes o torturar campesinos, no se dedique a estrangular mujeres. Cuídate del presidente de la República, del dueño de la fábrica de enfrente. Quizá ellos estén también jugando en el borde de su sistema, del que han creado y sobre el que permanecen como perros dogos, zopilotes cuidando sus carroñas. Cuídate de los milagros, de los militares, del cielo, de los apóstoles. Y si lo encuentras, y si él está loco y mata por necesidades más allá de ti, de mí, de nosotros, mátalo. No lo entregues a la policía, que ellos están en otro juego (Taibo Il, 1976: 15).

Belascoarán Shayne comenta que decidió convertirse en detective cuando una noche salió de ver en el cine El caso de Justin Playfair, un filme que dirigió en 1971 Anthony Harvey. La película cuenta la historia de un juez que a partir de la muerte de su esposa comienza a creer que es Sherlock Holmes. Su familia considera que está loco y decide someterlo a una atenta observación y control psiquiátrico. Así conoce a la Dra. Watson, con quien comienza a resolver misterios con el uso del método deductivo. En rigor de verdad, lo que lo inspira no es la historia que cuenta el filme (dice que podría haber visto cualquier otra película y hubiera tenido la misma revelación), sino descubrir que no quería continuar con una vida que consideraba cómoda, aburrida y sin sentido. Así, toma distancia del modelo del detective analítico y se inscribe en la tradición del hard-boiled.

Es, por tanto, una suerte de antihéroe que emprende en cada investigación una lucha contra el sistema corrupto de las instituciones mexicanas y falla una y otra vez. Este personaje, agobiado por la realidad que lo rodea, y que no logra comprender, se

2 En No habrá final feliz, explica que: "Me metí a detective porque no me gustaba el color que mi mujer quería para la alfombra. El diploma me lo dieron por trescientos pesos, y nunca leí novelas en inglés. Cuando alguien habla de huellas dactilares me suena propaganda de desodorante; con la pistola nomás le doy a lo que no se mueve mucho, y solo tengo 32 años" (Taibo II, 1989: 412). Las palabras del personaje cristalizan una concepción del detective como un sujeto común y su actividad como un trabajo que no es excepcional.

3 Recordemos, por ejemplo, cuando se reúne con Fuang Chu, el compañero de celda de Jesús Ma. Alvarado, la víctima cuyo crimen se propone aclarar en Muertos incómodos (2005), cuando se presenta como detective, el potencial testigo responde con un categórico: “¡No mames!”. En varias oportunidades tiene que ser enfático al momento de aclarar que es independiente por la desconfianza que generan las instituciones estatales.

4 El narrador de No habrá final feliz afirma: “Nebulosamente, Héctor, que nunca se había dado de hocico contra el poder, percibía al Estado como el gran castillo de la bruja de Blancanieves, del que salían no solo los Halcones, sino también los diplomas de ingeniero y la programación de Televisa" (Taibo, 1989: 482). No solo la ciudad de México es un monstruo como veremos en la segunda parte de este trabajo, sino también el Estado que se representa como una figura total que organiza la sociedad al tiempo que sostiene un orden con potencia de destrucción. 
interroga continuamente acerca de su rol en ese medio que habita y es consciente de que sus limitaciones lo ubican en el mismo rango que el ciudadano promedio mexicano. Así, a diferencia de los célebres detectives que se destacan por una racionalidad aguda y una sagacidad intelectual que los elevan a la categoría de individuos excepcionales, él es un sujeto que yerra, equivoca indicios y comete errores. Es decir, Taibo II produce una desmitificación del personaje ícono del género, el detective, que opera en varios ejes de su construcción.

Edifica una personalidad que va más allá de los estereotipos construidos en las grandes novelas del género, dotándolo de una compleja identidad que lo aproxima al imaginario mexicano contemporáneo y, a la vez, trasciende las convenciones sociales de esa misma cultura. Para ello, el autor se sirve de recursos como las descripciones cuantiosas, extensas, precisas y cargadas de matices, la recreación del habla de los ciudadanos de diferentes estamentos sociales de Ciudad de México, la minuciosidad en la construcción de diálogos en los que se entrecruzan esas voces sin perder el tono propio y los cambios inesperados de la voz narrativa.

El motivo que desata sus investigaciones no es el gusto por los acertijos, como en los detectives Sherlock Holmes o Auguste Dupin, sino más bien la inclinación a la búsqueda de justicia social. Los casos que lo interpelan siempre tienen como protagonistas a sujetos desfavorecidos que han sido víctimas de algún gesto criminal del sistema. Esto posibilita que el personaje despliegue su crítica sociopolítica y acentúa el cuestionamiento a las normas que generan exclusión y desigualdad en el ejercicio de los derechos ciudadanos. Es decir, en el universo de estas novelas, cada pesquisa opera como una reflexión crítica sobre la dinámica de las instituciones y promueve una toma de conciencia en los lectores acerca de cuáles son las acciones que originan los gestos criminales. Es posible afirmar que Taibo II construye un detective cuya misión última es develar el entramado criminal fundante de la sociedad burguesa y desentrañar las razones profundas que originan, estimulan y se benefician con el continuo funcionamiento de ese armazón delictivo.

A su vez, podemos leer cierta crítica a la masculinidad hegemónica (Connell, 2003) en la composición del personaje. La configuración del detective tensiona las prácticas asignadas a la masculinidad en la cultura mexicana y en la tradición detectivesca. La característica más relevante de Belascoarán, que se destaca desde el inicio de cada novela, es que el personaje es abstemio. Esto llama la atención del lector del género ya que las adicciones o prácticas autodestructivas son marcas distintivas de los detectives tradicionales (S. Holmes, S. Spade, P. Marlowe, K. Wallander y H. Hole, entre otros) y conmueve al estereotipo del hombre mexicano en el que el consumo de alcohol es sinónimo de virilidad.

Sin embargo, no es el alcoholismo la única práctica social de género que se cuestiona, sino que hace extensiva su crítica a otras conductas que avalan la posición dominante de los hombres dentro de la cultura popular mexicana:

Eran "esos mexicanos", gente que se hacinaba en familia dentro de un cuarto de seis por tres, que veía pacientemente a su padre cohabitar con su madre y que terminaba tirándose a su hermana por proximidad de cama, que estudiaba primaria y no la terminaba por lograr pescar chamba de mecánico que justificaba cierta libertad, un lugar en la familia, el derecho a embutirse seis cervezas las mañanas de los sábados, a pensar en casarse para repetir el ciclo (Ibíd.: 29).

En No habrá final feliz, el detective se involucra desde que recibe una nota con la frase "no te metas", un billete de avión y la fotografía de un hombre muerto. Esa intimidación provoca el efecto contrario al buscado: "- ¡Que se vaya a Nueva York 
su puta madre!" (Taibo II, 1989: 432). Por lo tanto, aquello que se presenta como una amenaza es leído como un reto y azuza al detective a iniciar su investigación. Esto nos permite considerar que la racionalidad analítica y científica no es lo que guía la construcción de la personalidad del detective y de su método, sino que van a tener mayor relevancia elementos ajenos y excluidos de la tradición genérica tales como la intuición y la terquedad. Componentes que pueden encontrarse fácilmente asociados y destacados en las descripciones heteronormativas de las lógicas cognitivas femeninas. En la concepción binaria occidental la intuición se presenta desligada de la razón, se le opone, e involucra el universo emotivo corporal de los sujetos y, por lo tanto, carece de rigor científico. ${ }^{5}$ El involucramiento del detective trasciende la lectura racional-analítica de los hechos. En Muertos incómodos (2005) el narrador precisa:

Héctor Belascoarán Shayne era mexicano, de tal manera que el absurdo no le espantaba. Era mexicano y tuerto, de manera que veía la mitad de lo que veían los demás mexicanos, pero con mayor precisión focal. En los últimos años había vivido en las fronteras, en el límite, de unos extraños territorios que bordeaban la incoherencia, la irracionalidad y la extravagancia, y también la tragedia, la pendejez, el agravio colectivo, la impunidad, el miedo y el ridículo. Territorios que eran cualquier cosa menos inocentes, en los que de repente se perdía un ojo, moría un amigo, te soltaban una descarga de escopeta cuando salías de comprar unas donas de chocolate. Territorios que retaban a la razón y que sin embargo estaban repletos de oscuras razones. El país era un gran negocio, un territorio convertido en botín por jinetes apocalípticos chafas y medio narcos; un supermercado gerenteado por un Federico Nietzsche pedo, muy pedo, donde nada era lo que parecía (Taibo Il y Subcomandante Insurgente Marcos, 2005: 46).

No es el sujeto que resuelve los casos con el único propósito de demostrar los alcances de su inteligencia y reafirmar su singularidad en medio del caos de la vida moderna, sino aquel que se declara a la vez agente y quien padece de la irracionalidad constitutiva de una sociedad particular. A su vez, no ostenta una moral conservadora que impulse acciones restitutivas de un orden perdido, sino que concibe su gesta como revolucionaria ya que busca construir un nuevo orden social en el que la justicia defienda y proteja la vida de los excluidos de un sistema que ha sido injusto desde sus orígenes.

Este movimiento liga estas novelas de Taibo II a la tradición inaugurada por los escritores Dashiell Hammett y Raymond Chandler, quienes introducen en la narración policíaca la vertiente del realismo crítico que denuncia el mal estado de la sociedad en un momento determinado e inauguran dentro del policial el gran subgénero Novela Negra. Paula García Talaván (2014) señala que en este subgénero histórico es preponderante el componente ético, antes que el estético. Asimismo, modifica la construcción de las fórmulas narrativas, y como consecuencia el detective se vuelve duro, marginal, tiene una moralidad ambigua y es dueño de un cinismo y de una ironía que lo oponen a la sociedad. Agrega que:

Al contrario del detective clásico, el nuevo es vulnerable, se mete de lleno en la acción y sufre físicamente sus consecuencias. Para él la investigación no es un puro juego intelectual sino una toma de postura ética. También varía el rígido esquema de oposición entre los principios del Bien y del Mal encarnados en los personajes

5 Caruncho y Mayobre sostienen que "todo el pensamiento occidental está fundamentado en toda una serie de dicotomías: mujer versus hombre, naturaleza versus cultura, privado versus público, reproducción versus producción, intuición versus razón, cuerpo versus intelecto" (1998: 157). Dicha visión dicotómica de la realidad tiene como consecuencia una jerarquización de las partes en la que se asocia a la mujer con los términos menos prestigiosos. De esa manera, la mujer se concibe con la naturaleza, con el ámbito privado, con la reproducción, con la intuición y con el cuerpo, mientras que el varón está cerca de la cultura, de la esfera pública, del ámbito de la producción y de la razón. 
del detective y del criminal, respectivamente. No se trata ya de valores absolutos, sino relativos; no hay personajes enteramente malvados o enteramente buenos (2014: 69).

Es válido señalar aquí que el escritor mexicano escoge distanciarse de la Novela Negra tradicional y acuña el término Neopolicial para referirse a este género policiaco nuevo, en el que ubica su obra, que se caracteriza por "la obsesión por las ciudades; una incidencia recurrente temática de los problemas del Estado como generador del crimen, la corrupción, la arbitrariedad política" (Argüelles, 1990: 14). Así, este nuevo género conserva su vínculo estrecho con la literatura popular y, a la vez, se distancia de la clásica Novela Negra al impugnar la legalidad del sistema estatal y poner en evidencia la corrupción inherente a las instituciones de gobierno. Taibo II señala que el neopolicial no se opone al policiaco tradicional, sino que es una variante del mismo:

Lo que supongo que es la variante fundamental es que se abandonó una novela cuyo eje central era la anécdota. El neopoliciaco rompió con la tradición de una novela basada fundamentalmente en la anécdota y abrió las puertas experimentales hacia una novela cuyo eje central es la atmósfera. Esa sería la gran diferencia (Ramírez; Rodríguez-Sifontes, 1992: 47).

En la entrevista realizada por Juan Ramírez y Verónica Rodríguez-Sifontes, Paco Ignacio Taibo II sostiene que un detective de los 90 en México es "surrealista, se mueve entre una doble tensión" (Ibíd.: 42), entre los datos de una realidad marcada por la violencia y los abusos de poder y una "propuesta neorromántica de ajustar la realidad a partir de crear justicia en el acto individual colaborando con lo social"( Ibíd.: 43) y propone que así la escritura se transforma en una apuesta "realista neorromántica" que posibilita la emergencia de un personaje híbrido e irracional desde el punto de vista tradicional. Belascoarán rechaza el raciocinio y en su lugar ofrece su cuerpo: las cicatrices operan como una declaración de protesta.

Braham encuentra una notable influencia de la obra de Chester Himes en estas novelas de Paco Ignacio Taibo II. Los célebres detectives de Himes, Grave Digger Jones y Coffin Ed Johnson también exhiben las marcas de su enfrentamiento a un orden social injusto, violento y caótico: "More than mere battle scars, these marks are the physical inscriptions of the bearers' marginalized, absurd engagement with a brutal society" (Braham, 2004: 91). Pero la proximidad de estas obras se encuentra no solo en la primacía de la acción por sobre la razón, sino que en ellas se combate la retórica de la víctima. Por un lado, la idea de la persona negra sometida por una sociedad racista y, por el otro, la mítica figura del hijo de la chingada. Los escritos de Himes y de Paco Ignacio Taibo II revierten esa configuración y presentan un universo ficcional donde el negro y el mexicano también cometen crímenes.

Con respecto a las características más destacadas de su detective, Taibo II resalta su "locura mexicana" que se asienta en la imposibilidad de interpretar el mundo desde la siempre limitada razón occidental. El personaje confía en la terquedad y en la tenacidad y es escéptico de que alguna ciencia aproxime a un mexicano a descubrir la verdad porque "hay una entropía de la mentira en este país. Por lo tanto, todo lo que sucede tiende a distorsionarse o a convertirse en falso, todo a enmascararse" (Ibíd.: 43). Es en ese sentido que el protagonista se distancia en sus métodos de la indagación que propone la razón científica y recurre a una sensibilidad anclada en la

6 Algunas de sus obras han sido llevadas al cine y fueron parte del movimiento cinematográfico de Blaxploitation como Cotton comes to Harlem (1970) (disponible en: https://www.youtube.com/watch?v=6zXoPvef6Rs\&t=2610s) y Come Back Charleston Blue (1972) (disponible en: https://www.youtube.com/watch?v=vmLoiqJXorg). 
emotividad latinoamericana que siempre excede el binarismo y encuentra en la fuga hacia lo múltiple la posibilidad de arribar a explicaciones más complejas y verdaderas.

\section{Ciudad de México: el espacio y la lógica patriarcal}

El espacio urbano moderno ha sido el escenario escogido por la tradición del género desde sus inicios y, como señala Román Setton (2011:194), grandes pensadores como Benjamin, Bloch y Kracauer han coincidido en señalar que "El desconocimiento del prójimo, la pérdida de la relación del hombre con la trascendencia, la escisión entre el sujeto privado y su vida pública", que propicia la ciudad moderna han hecho posible el surgimiento del género. Sin embargo, como advierte Setton, esos elementos pueden pensarse como necesarios para el surgimiento de una narrativa que tematiza los conflictos propios de espacios urbanos, pero en modo alguno es posible atribuirles el origen de una forma que narra dos historias (la del crimen y la de su descubrimiento y reconstrucción) de manera paralela trazando diversos recorridos por el espacio de las ciudades y haciendo confluir las dimensiones espacio y tiempo.

Sin embargo, es innegable la presencia destacada de la ciudad, en el género y la incidencia de su configuración en el plano de las historias narradas. Así, es posible señalar que las aventuras de Holmes, los relatos de Poe, las aventuras de Mario Conde y las investigaciones de Pepe Carvalho no tendrían igual resolución fuera de Londres, París, La Habana o Barcelona ya que las singularidades de esos espacios aportan las motivaciones y elementos para el origen y la resolución de conflictos que, en apariencia, no se diferencian radicalmente entre sí.

En estas novelas de Paco Ignacio Taibo II, Ciudad de México no es solo el escenario central de las aventuras, sino que es parte constitutiva del protagonista y, como tal, define sus actos otorgándole una identidad sin restarle universalismo a las diferentes problemáticas que se anudan en la resolución de los conflictos. La ciudad actúa como emisora de estímulos a los que el detective responde con movimientos de oscilación entre el rechazo y el reconocimiento o apropiación.

Es decir, Belascoarán Shayne reconoce aspectos socioculturales que le permiten establecer constantes en las dinámicas relacionales de los sujetos y, a la vez, lucha contra aquellos que atentan contra la ética vital que guía los actos del detective y que propician acontecimientos antisociales. Las largas caminatas, el viaje en transporte público y el internarse en las multitudes son desplazamientos habituales que propician sus cavilaciones y le permiten exponer comportamientos y valores condenables sin preámbulos ni aspavientos. Perderse en la ciudad recibiendo los estímulos de su ritmo alocado y recalar en sus cafés y parques para reflexionar sobre los casos que lo ocupan y sobre conflictos personales es un ejercicio habitual que constituye el método de este detective: "Sin saber cómo, volvió al centro de la ciudad, en horas de tiendas, compras, claxonazos, luces y más luces. Se sentía arropado en el tumulto; anónimo en el bullicio concentraba su fuerza en el interior de su cabeza" (Taibo II, 1989: 412).

De modo que la percepción del investigador se ve estimulada en los espacios ruidosos, caóticos y coloridos. Como contrapartida, recurre a los espacios menos concurridos para analizar y sistematizar sus descubrimientos y reflexionar sobre causas y consecuencias que podrían derivarse de sus conclusiones. Vale detenerse aquí para señalar

7 Para Simmel (1986) la metrópoli provee, a la vez, la arena para la lucha entre lo subjetivo y lo objetivo y su reconciliación, pues presenta las condiciones peculiares que aparecen como oportunidades y estímulos para el desarrollo de ambas tendencias. De este modo, en la metrópolis se desarrolla también la tensión máxima entre libertad y enajenación. Una tensión que, más allá de la tendencia a la hipertrofia de la cultura objetiva, no se resuelve, es un juego abierto. 
que esta preferencia por los espacios abiertos, públicos y más silenciosos como plazas y parques puede vincularse con esos giros cuestionadores a la racionalidad hiperviralizada que hemos señalado.

Tal como los estudiosos de la geografía humana, Massey (1998) y Smith (1984) entre otros, vienen indicando en las últimas décadas, los espacios o lugares surgen de las relaciones de poder. Éstas establecen las normas; y las normas definen los límites, que son tanto sociales como espaciales, porque prescriben quién pertenece a un lugar y quién queda excluido. En este sentido, vale señalar que la asignación de "espacios propios" opera como una regulación de las relaciones de género y de los desplazamientos de los cuerpos por los territorios geográficos.

De manera que hay una delimitación de espacios discursivos y socioculturales a los que pueden acceder, y desde los cuales pueden intervenir, los individuos pertenecientes a los diferentes géneros, así como espacios físicos y geográficos habilitados para el tránsito o la permanencia de éstos. En otras palabras, los espacios urbanos no son neutrales, sino que expresan en su organización procesos sociales de asignación de roles genéricos. Como señala Molina (2006: 14):

aún cuando el sello masculino del espacio construido no necesariamente condicione nuestras vidas de forma determinante, hay una serie de valores simbólicos asociados a este, que influyen de forma directa o indirecta en nuestro diario vivir.

Así, en la estructura urbana moderna occidental son las lógicas patriarcales las que sustentan la organización y funcionamiento de los espacios respondiendo a la diferenciación entre productivo y reproductivo en la que el último término se asigna a lo femenino y el primero a lo masculino. De este modo, los espacios de aquietamiento como parques y plazas están destinados a las prácticas de cuidado y esparcimiento y, por lo tanto, los sujetos que pueblan esos espacios son mujeres o niños.

En relación con lo antedicho, el vínculo con el espacio urbano que establece este detective se distancia de los que establecen los personajes reconocidos del género al decantarse por un lugar público para sistematizar sus indagaciones y, dentro de esta categoría, escoger un sitio asignado a los roles de cuidado y esparcimiento que se atribuyen a lo femenino. Esta preferencia se suma a la asunción de un método de investigación en el que, como ya señalamos, se asigna gran relevancia a la intuición y se asume la confusión frente a los enigmas sin dar muestras de una superioridad cognitiva racional frente a las instituciones e individuos con los que interactúa, sino que se insiste tercamente en indagar allí donde la razón no llega.

\section{Experimentación y género(s): una novela escrita a cuatro manos}

En su lectura sobre el género policial, Daniel Link (2003: 5) se sirve de la noción de perceptrón, categoría que da vigor a su argumento y le permite sostener que la literatura: "es una poderosa máquina que procesa o fabrica percepciones, un "perceptrón» que permitiría analizar el modo en que una sociedad, en un momento determinado, se imagina a sí misma". La literatura percibe un estado de la imaginación que le permite captar zonas problemáticas del presente. De manera que las obras literarias condensan una serie de problemas que dan vueltas en los imaginarios sociales y, en este caso en particular, advertimos en el corpus una creciente y cada vez más elaborada interpretación tanto social como sexual de México.

De las tres novelas que abordamos, sin dudas es la última, Muertos incómodos la que más apuesta a la experimentación. Desde la alternancia de narradores en tercera y 
segunda persona, los cambios en las perspectivas, capítulos que se componen íntegramente de citas (de personajes literarios de esa obra y otras, de figuras de la política nacional e internacional, etc.), hasta el procedimiento de la metaficción. Parece haber una correspondencia entre el ensayo cada vez más atrevido con la experimentación y una creciente complejidad en relación con la diversidad de género en el sentido de matriz de identidad que presenta el corpus.

Sobre todo, la última novela de la saga nos invita a preguntarnos por los modos que asume en la ficción la configuración de las masculinidades. Es pertinente comentar en este punto que los orígenes de la discusión sobre el rol masculino se remontan a los debates que se dieron en el siglo XIX sobre las diferencias sexuales. Aunque recién en la década del 20 se comenzó a usar el concepto "papel o rol" para explicar el comportamiento social. Esta noción suponía que ser un hombre o una mujer significaba poner a funcionar una serie general de expectativas asignadas a cada género sexual.' Desde los años 60 el feminismo cuestionó el concepto de "rol sexual" debido a que consideraba que la invención del rol se convirtió en una herramienta política que definía un problema, motivo por el cual comenzó a sugerir estrategias para la reforma.

Cuando hablamos de masculinidades resulta ineludible la referencia a los trabajos de R. W. Connell. La socióloga australiana se pregunta si la masculinidad es o no un objeto de conocimiento coherente al tiempo que se interroga por las prácticas que permiten que este tipo de conocimientos emerjan. Desde los trabajos de Freud en los que indaga la oposición entre lo femenino y lo masculino, advierte que se trata de conceptos confusos, escurridizos y difíciles de definir, hasta las más recientes teorías posfeministas, en los que percibe cierto acuerdo en que el concepto de género depende del momento histórico y se carga de sentido políticamente. Para Connell, por lo tanto, la masculinidad puede entenderse como una unidad heterogénea y amorfa, pero con un carácter opresivo denominado patriarcado.

Es innegable en la actualidad la relevancia social y política del término género. Se trata de una noción que ha proporcionado una herramienta emancipatoria tanto a las luchas de los movimientos de mujeres como a los colectivos LGBTIQ+. ${ }^{10}$ Los términos de género se cuestionan porque discursos y sistemas de conocimiento en conflicto se disputan el derecho a explicarlos. En este sentido, para Connell (2003: 72) las masculinidades funcionan como configuraciones de la práctica determinadas por las relaciones de género: "Son inherentemente históricas y se hacen y rehacen como un proceso político que afecta el equilibrio de intereses de la sociedad y la dirección del cambio social".

La novela que completa la serie fue escrita por Taibo II y el Subcomandante Insurgente Marcos en el año 2005. En entrevistas y conferencias, el autor hispano-mexicano ha comentado lo conforme que quedó con la obra, pero advierte que no volvería a hacer algo así debido a las singulares condiciones en que se realizó la novela. En cuanto a la manera en que se resolvió la escritura, el dirigente social escribió los capítulos impares mientras que Taibo II se encargó de los pares. Más allá de las claras diferencias entre sus estilos de escritura, resulta evidente que la obra tiene una sugestiva vitalidad,

8 El recurso de la cita literaria y de la metaficción se explora y explota con mayor contundencia en el capítulo 9 de Muertos incómodo, en el que se define el Mal y el Malo. Nociones hermanadas y medulares para comprender quién es el enemigo desde la primera novela hasta el final de la serie, algo que Carlos Brian ya había señalado, tal como se puede ver en la primera cita de este trabajo.

9 En relación con esto podemos agregar que la idea de masculinidad en tanto internalización del rol sexual masculino permite el cambio social ya que esos rasgos que se le asocian pueden ser revisados y deconstruidos.

10 Mattio (2012) identifica y analiza dos tradiciones del término género: por un lado, una tradicional que lo distingue del término sexo y, por otro, una feminista materialista y del transfeminismo que lo vincula con los orígenes biomédicos. El filósofo indaga los aportes, las discusiones y las transformaciones de ambas líneas y advierte los alcances de dicho proceso de desarrollo. 
que el trabajo con la forma es orgánicamente osado y lúdico y que la transgresión es condición de la obra.

Los autores construyen las historias del investigador y de Elías Contreras, un "comisión de investigación". A partir de una serie de llamadas que supuestamente provienen de un militante estudiantil asesinado en 1971, el detective indaga el paradero de un tal "Morales" participante de crímenes protagonizados a la sombra del aparato estatal mexicano. Al mismo tiempo, en la selva chiapaneca, Elías Contreras rastrea a un tal "Morales", quien, según unos papeles del novelista español Manuel Vázquez Montalbán, estaba involucrado en misteriosas operaciones criminales en los últimos años.

La aparición de los papeles de Vázquez Montalbán opera como un disparador de la historia de Elías Contreras. Este material llega de manos de Pepe Carvalho, célebre personaje que protagoniza la serie de novelas del fallecido autor español. Con ese giro hay una torsión en la ficción que evidencia un entrecruzamiento de planos. Este procedimiento se intensifica con la aparición y las intervenciones del Club del Calendario Roto. ${ }^{11}$ Uno de sus miembros asume la voz de narrador y le pregunta al autor de esta novela si iban a acompañar a Elías en la novela, el Sup. le respondió que no y él concluyó:

Así que hasta aquí nomás llegamos. Ahora, para saber qué va a pasar, tendremos que esperar a leer los siguientes capítulos de la novela. iJoder! De todas maneras, no sé ustedes, pero yo ya estoy cansado de esas novelas policiacas donde todos los personajes son muy inteligentes y cultos, y el único tonto e ignorante es el lector. No sé si tontos, pero aquí todos somos ignorantes... porque siempre falta lo que falta (Taibo II; Subcomandante Insurgente Marcos, 2005: 40).

Quien habla es Juli@ Isileko, un joven mecánico filipino que solo aparece en el tercer capítulo. Allí explica que su nombre se escribe con una arroba porque es homosexual: "sí, soy gay, homosexual, maricón, florecita, puto, mampo, mariposón, joto, puñal o como se diga en sus mundos de cada quien" (Ibíd.: 27). Juli@ vacila en decir que es gay porque no cree que sea ni necesario ni conveniente: "porque ya ven que luego asocian «homosexual» con «criminal»" (Íd.). Esta serie de apreciaciones que no tienen relación con los casos que se están por investigar devienen llamativas porque encierran una concepción de lo literario como configuración crítica de lo real. En las palabras del personaje se asoman un conjunto de percepciones en torno al género y a la sexualidad que permiten leer el presente.

Pero acaso un personaje que resulta también iluminador es Magdalena, una travesti con quien Elías establece una alianza y que se vuelve una pieza fundamental al momento de resolver el caso y de obtener justicia. En el capítulo 7, Elías reflexiona: "Y no dormí porque estuve pensando que a veces el Dios también se equivoca, porque a la Magdalena, que es mujer, la puso en cuerpo de hombre" (Ibíd.: 76). Cada vez que se refiere a ella alterna las formas del masculino y del femenino, lo cual podría interpretarse como un detalle sin importancia, pero si tenemos en cuenta que una particularidad de Elías Contreras es la atención que le presta al lenguaje, ${ }^{12}$ cabe preguntarse qué hay detrás de esa recurrencia.

11 Son los miembros de este club quienes discuten acerca de las inciertas motivaciones que tiene Elías Contreras para ir al Monstruo, manera en la que se refieren a Ciudad de México. Esbozan diferentes teorías, mientras que algunos creen que el detective aficionado irá en busca de medicinas o a comprar entradas a un espectáculo de jazz: "Mayo Clandestino alegaba que no, que Elías iba a averiguar la dirección de un hospital donde hacían operaciones de cambio de sexo, porque el Sup. es lesbiano, o sea que le gustan las mujeres pero no le hacen caso y se iba a hacer mujer para que lo quisieran. Yo, o sea Julio Secreto, dije que Elías iba para averiguar cuándo era la Marcha del Orgullo Gay en la que el Sup. se haría presente y saldría, simultáneamente, de la selva y del clóset" (Taibo II; Subcomandante Insurgente Marcos, 2005: 34). La discusión sobre la sexualidad del Subcomandante Marcos concluye cuando acuerdan que el autor de la novela es: "más machito que Pedro Infante" (Íd.).

12 No perdamos de vista el análisis que hace sobre los pares lingüísticos caso/cosa, detective/comisión de cargo y colegas/colegos. Así como la manera en que se apropia de palabras que no conocía (perspectiva y susodicho) y se 
Magdalena protege a Elías Contreras desde el momento en que se encuentran por primera vez (logra distraer a unos judiciales que lo interrogaban con violencia), abandona el Monstruo y va con él en busca de Morales, lo encuentran y gracias a ella los miembros de NADIE, una especie de comando especial y ultrasecreto, logran apresarlo. En esa acción matan a Magdalena. Sin embargo, es su intervención en otro momento de la obra la que merece ser revisada. En el capítulo 9, una serie de personajes participa de la novela con definiciones personales sobre qué es el Mal y quién es el Malo. Cuando le llega el turno a Magdalena, le plantea a Elías que él la comprenderá porque es indígena y sabe lo que se siente la discriminación.

A continuación, se refiere a los casos de Digna Ochoa y Pável González. Los asesinatos de estos dos activistas en 2001 y 2004, cuyas muertes tuvieron como respuesta del Estado la impunidad de sus homicidas, ${ }^{13}$ le sirven a Magdalena para representar al verdadero enemigo. Comprende que Morales es un simple instrumento que le permite a un poder superior disciplinar los cuerpos. Cuando esos cuerpos se distancian de los supuestos de "normalidad", son castigados con saña.

Los juegos formales (con frecuencia ligados a las torsiones lingüísticas) trazan un mapa imaginario que nos permite acercarnos a la comprensión de un conjunto de problemas inscriptos en la intervención de los cuerpos, en la diversidad de las sexualidades y en los géneros. En relación con lo señalado, resuenan las palabras de Taibo II (1989: 401) en la nota del autor de No habráfinal feliz: "Evidentemente, la historia y los nombres que se manejan en esta novela pertenecen al reino de la ficción. El país, sin embargo, aunque cuesta trabajo creerlo, es absolutamente real".

Pero no solo en esta obra escrita a cuatro manos encontramos un corrimiento de la concepción típica del género (entendido como matriz de identidad y como forma literaria) de la novela negra. En la producción de autores como Dashiell Hammett y Raymond Chandler, que funcionaron como antecedentes literarios del filme noir, se incorpora la figura de la femme fatale. La mujer no es confiable porque usa al detective, le miente, lo seduce y manipula, y conduce a sus víctimas a situaciones de peligro o incluso a la muerte. Esto no sucede en las novelas que abordamos.

Muy por el contrario, las mujeres operan como aliadas fundamentales, no contribuyen marginalmente a la resolución de los casos, sino que acercan información que deviene central para acercarse a la verdad o intervienen en momentos decisivos en los que la vida de Belascoarán está en peligro. Pero, además, los relatos de sus vidas tienen un espacio en medio de las investigaciones. Sabemos, por ejemplo, las motivaciones de Elisa, la hermana del protagonista, para regresar a México y abandonar la vida doméstica que tenía con su marido en Canadá:

Además, me había convertido en una ama de casa moderna, pero ama de casa al fin y al cabo, dependiente, inútil por tanto. Si algo supe hacer, ya casi estaba olvidado. $Y$ ahí me tienes a los veinticuatro años, de nuevo soltera, sin hijos, más vapuleada que un león después de haber peleado con Tarzán, solitaria, con rudimentarios conocimientos de taquigrafía, despolitizada a más no poder, porque Canadá se presta para volverte clase media hasta el tuétano. Todo lo que viví en el 68 está oculto en la azotea que me queda por cabeza (Taibo II, 1976: 44).

Al igual que su hermano cuando tuvo una epifanía al salir del cine con su esposa, Elisa comprende que su vida tomó un rumbo que no la satisfacía, que la adormecía

esmera por incorporarlas al vocabulario propio y al de su gente.

${ }_{13}$ Cf. Taibo II y Subcomandante Insurgente Marcos (2005: 96): “las autoridades dijeron que ella era lesbiana y que el Pável era homosexual, como si eso fuera un argumento para no hacer justicia”. 
en tanto sujeto político. Algo parecido podemos observar en el quinto capítulo de Días de combate, cuando la muchacha de la cola de caballo cuenta su historia. Además de los detalles escabrosos de su familia, Irene relata en una segunda persona que su padre fue un dirigente del sindicato de Trabajadores de Obras Públicas que se vendió al gobierno. Su gesto de rebelión fue la militancia: "El movimiento del 68 se rompió dentro de ti como un cajón de copas finas." (Taibo II, 1976: 33). Las mujeres son así sujetos complejos, con intereses que van más allá de lo sentimental, y ayudan a impartir justicia allí donde la ley se ha ausentado.

El detective de la novela negra tiene una actitud irreverente, es seguro, gracioso, involucra su cuerpo y su seguridad y, aunque a veces se equivoca y por eso recibe palizas o termina en una celda, no se muestra temeroso ni vacila en su accionar. Es un personaje solitario que solo establece vínculos frágiles e inestables. Aunque su principal motivación es el dinero, tiene unos principios morales que no le permiten dejarse sobornar, pero tampoco vacila si considera que es necesario asesinar. El férreo código de conducta de personajes como Sam Spade o Philip Marlowe reaparece en el detective creado por Paco Ignacio Taibo II.

No obstante, en algo se diferencian de modo notable, en el temor. En especial en No habráfinal feliz, obra en la que nuestro detective es asesinado por una red de policías corruptos, el protagonista lamenta su soledad y decide casarse con la muchacha de la coleta, pero ella lo abandona. No solo el título anticipa el trágico final, a lo largo del relato, el detective manifiesta con frecuencia que siente miedo no solo a morir, sino que le asusta la vida que lleva. A la acción se le intercalan breves, pero recurrentes espacios reflexivos que llevan al personaje a entrar en conflicto consigo mismo. Belascoarán se configura como un sujeto que vacila, abrumado por la amargura y la desolación, que solo encuentra una fugaz tranquilidad al imaginar una vida fuera del peligro.

Como señala Eribon (2017:16), los textos literarios desarrollan complejas teorizaciones sobre los géneros y las sexualidades "apelando a estrategias literarias y narrativas para referirse a realidades siempre "escandalosas". De este modo, la literatura logra dar cuenta de la inestabilidad de las teorías de género y de la constante disputa por los sentidos en el campo discursivo de las sexualidades y las identidades. Es así que en este corpus de novelas de Paco Ignacio Taibo II hemos podido identificar estrategias formales que ponen en juego puntos de vista diversos y se distancian de los sentidos tradicionales respecto a las identidades del detective, de los géneros y de la cultura mexicana. Consideramos que estas piezas literarias permiten descubrir otros sentidos con respecto a las postulaciones discursivas formuladas desde espacios epistemológicos institucionales y amplían el universo de las masculinidades en la literatura policial.

14 Irene, la muchacha de la cola de caballo, mató al Márquez Thiess, el asesino serial de la primera novela, después de que HBS fallara cuando le disparó con su pistola: "Salía corriendo de la casa. Me había acercado desde antes, ol los tiros. Venía inclinado, como si trajese una herida. Pasó frente a mí y lo pateé en la pierna. Con el impulso fue a dar a la reja y quedó ahí, ensartado. ¿Era el estrangulador? —Él era" (Taibo II, 1976: 88). 


\section{Bibliografía}

》 Argüelles, J. D. (1990). “Entrevista con Paco Ignacio Taibo II. El policiaco mexicano: un género hecho con un autor y terquedad”. Tierra adentro, $\mathrm{N}^{\circ} 49$ (septiembre-octubre), 13-15.

" Balibrea-Enríquez, M. P. (1996). “Paco Ignacio Taibo Il y la reconstrucción del espacio cultural mexicano". Confluencia, 12 (1), 38-56.

»Braham, P. (2004). Crimes against the State, Crimes against Persons. Detective Fiction in Cuba and Mexico. Minnesota: University of Minnesota Press.

»Caruncho, C. y Mayobre, P. (1998). "El problema de la identidad femenina y los nuevos mitos". En: Caruncho, C. y Mayobre, P. (coord.). Novos Dereitos: Igualdade, Diversidade e Disidencia. Santiago de Compostela: Ed. Tórculo, pp. $155-172$.

"Connell, R. W. (2003). Masculinidades. Ciudad de México: UNAM.

»Eribon, D. (2017). Teorías de la literatura. Sistema del género y veredictos sexuales. Buenos Aires: Walduther.

» Escribà, Á. M. y J. S. Zapatero. (2008). “Una mirada al neopolicial latinoamericano: Mempo Giardinelli, Leonardo Padura y Paco Ignacio Taibo II”. Anales de literatura hispanoamericana, V 36, 49-58.

" García Talaván, P. (2014). "La novela neopolicial latinoamericana: una revuelta ético-estética del género”. Cuadernos Americanos: Nueva Época, 2 (148), 63-85.

»Link, D. (comp.) (2003). El juego de los cautos. Buenos Aires: La Marca.

»Mattio, E. “¿De qué hablamos cuando hablamos de género? Una introducción conceptual”. En: Morán Faúndes, J.; Sgró Ruata, C.; Vaggione, J. (eds.), Sexualidades, desigualdades y derechos. Reflexiones en torno a los derechos sexuales y reproductivos. (2012). Córdoba: Ciencia, Derecho y Sociedad.

» Massey, D., \& Bernal, G. (1998). “Espacio, lugar y género”. Debate Feminista, 17, 39-46.

"Molina, I. (Ed.). (2006). Rompiendo barreras: género y espacio en el campo y la ciudad. Santiago: Ediciones El Tercer Actor.

» Nichols, William J. (2000). “Nostalgia, novela negra y la recuperación del pasado en Paco Ignacio Taibo II". Revista de Literatura Mexicana Contemporánea no 13, 96-103.

»Ramírez, J. C., \& Rodríguez-Sifontes, V. (1992). “Paco Ignacio Taibo II: La lógica de la terquedad o la variante mexicana de una locura”. Mester nº 21 (1), 41-50.

"Setton, R. (2011). "Pensar la literatura policial: Siegfried Kracauer, Walter Benjamin, Ernst Bloch, el género y la disolución de los vínculos comunitarios." Constelaciones: Revista de Teoría Crítica, 3, 193-207.

" Simmel, G. (1986). El individuo y la libertad. Ensayos de crítica de la cultura. Barcelona: Península.

"Smith, N. (2010). Uneven Development: Nature, Capital, and the Production of Space. Georgia: University of Georgia Press.

»Taibo II, P. I. (1976). Días de combate. En: https://es.scribd.com/ 
document/225883927/Dias-de-Combate-Paco-Ignacio-Taibo-Ilhttps:// es.scribd.com/document/225883927/Dias-de-Combate-Paco-Ignacio-Taibo-II.

"Taibo II, P. I. (1989). No habrá final feliz. En: http://homepages.neiu. edu/ bpbisbey/SPAN 419/Taibo No habra final feliz.pdfhttp://homepages. neiu.edu/ bpbisbey/SPAN\%20419/Taibo\%20No\%2ohabra\%2ofinal\%2ofeliz. pdf.

» Taibo II, P. I. y Subcomandante Insurgente Marcos. (2005). Muertos incómodos. En: https://www.ebookelo.com/ebook/48652/muertos-incomodos. 